\title{
Perancangan dan Pembuatan Aplikasi Visualisasi 3D Interaktif Masjid Agung Jawa Tengah Menggunakan Unity3D
}

\author{
Irham Fa'idh Faiztyan ${ }^{1)}$, R. Rizal Isnanto ${ }^{2)}$, Didik Eko Widianto ${ }^{2)}$ \\ Program Studi Sistem Komputer, Fakultas Teknik, Universitas Diponegoro \\ Jln. Prof. Sudharto, Tembalang, Semarang, Indonesia \\ Email: faiztyan.irham@yahoo.co.id
}

\begin{abstract}
Previously, people who want to visit a tourist attraction should come to that place. If you can't visit it normally, you can only read or heard from a source. Therefore made 3-dimensional visualization application. The object to be visualized in this research is Great Mosque of Central Java. This application aims to facilitate the introduction of the Great Mosque of Central Java.

This application is created using Unity $3 D$ and Sketchup software, where the programming language used is UnityScript and JavaScript. The design phase made using Multimedia Development Life Cycle, and then proceed with the design using Flowchart. Implementation phase is done by implementing a 3D model and program implementation. The testing phase is done with a black-box method, as well as testing of the frame rate per second, memory and processor usage, how long rendering process, and user testing.

The results show that this application runs well on Windows operating systems. Buttons and functions within the application has been running well with the respective functionality. From the test results on the application of the Great Mosque of Central Java visualization can be shown that the process of rendering both real time and non real time rendering requires a high performance from graphics card and processor. Based on the testing that has been done, the application is quite easy to run by the user, the objects that exist in the application is quite similar to the original object, and this application provides benefits to its users.
\end{abstract}

Keywords: $3 D$ visualization, application, Unity3D, Great Mosque of Central Java

\section{PENDAHULUAN}

$\mathrm{S}$ emakin berkembangnya teknologi pada masa kini berbanding lurus dengan pola kehidupan masyarakat yang semakin sibuk. Masyarakat kini sudah sangat jarang mengunjungi objek yang memiliki nilai sejarah dikarenakan berbagai faktor kendala, di antaranya kendala pada waktu, jarak, uang, maupun kurangnya minat masyarakat sekarang pada objek wisata tersebut.
Untuk mengatasi agar paradigma tersebut tidak menjalar pada masyarakat maka perlu dilakukan penyampaian informasi kepada masyarakat tentang objek wisata melalui cara yang lebih modern. Misalnya dengan menggunakan kemajuan teknologi 3 dimensi sebagai alat untuk membuat aplikasi visualisasi 3 dimensi objek wisata. Nantinya dalam aplikasi tersebut akan dilengkapi berbagai informasi mengenai objek tersebut yang dikemas dengan antarmuka yang menarik sehingga menarik minat masyarakat untuk mencoba menggunakannya dan nantinya diharapkan akan menjadikan masyarakat tertarik dan akan mendatangi tempat tersebut.

Pada penelitian ini digunakan pemodelan 3 dimensi karena memiliki banyak kelebihan dibandingkan dengan model 2 dimensi. Kelebihan model 3 dimensi menurut Moedjiono yaitu media tiga dimensi memiliki kelebihan-kelebihan: memberikan pengalaman secara langsung, penyajian secara kongkrit dan menghindari verbalisme, dapat menunjukkan obyek secara utuh baik konstruksi maupun cara kerjanya, dapat memperlihatkan struktur organisasi secara jelas, dapat menunjukkan alur suatu proses secara jelas.

\section{DASAR TEORI}

\section{A. Masjid Agung Jawa Tengah}

Pengertian kepariwisataan menurut Gamal adalah suatu proses kepergian sementara dari seseorang, menuju ketempat lain diluar tempat tinggalnya. Dorongan kepergiannya adalah karena berbagai kepentingan baik karena kepentingan ekonomi, sosial, budaya, politik, agama, kesehatan maupun kepentingan lain.

Pariwisata sendiri terbagi menjadi beberapa jenis diantaranya pariwisata kesenian dan budaya, religi, sejarah, maupun alam. Jawa Tengah khususnya kota Semarang mempunyai pariwisata religi yang cukup banyak dan patut untuk dijadikan tujuan pariwisata selanjutnya. Salah satu yang terkenal adalah Masjid Agung Jawa Tengah (MAJT). 
Kompleks Masjid Agung Jawa Tengah terletak di Jalan Gajah Raya, Kelurahan Sambirejo, Kecamatan Gayangsari, Kota Semarang. Kompleks Masjid Agung Jawa Tengah sangat megah dan luas dengan luas lahan mencapai 10 Hektar dan luas bangunan untuk shalat 7669 meter persegi. Pembangunan Masjid Agung Jawa Tengah ini dimulai pada tanggal 6 September 2002 hingga akhirnya diresmikan oleh Presiden Republik Indonesia Bapak Susilo Bambang Yudhoyono pada tanggal 14 November 2006.

\section{B. Pemodelan $3 D$}

Objek 3D atau objek tiga dimensi adalah sebuah objek / ruang yang memiliki panjang, lebar dan tinggi yang memiliki bentuk. 3D tidak hanya digunakan dalam matematika dan fisika saja melainkan dibidang grafis, seni, animasi, komputer dan lain-lain.

Dalam grafik komputer 3D, modeling 3D adalah suatu proses menciptakan objek 3D yang ingin dituangkan dalam bentuk visual nyata melalui perangkat lunak tertentu.

\section{Rendering}

Rendering adalah proses akhir dari proses pemodelan dimana semua data-data yang sudah dimasukkan dalam proses modeling, animasi, teksturing, pencahayaan, akan diterjemahkan dalam bentuk output tampilan akhir pada model dan animasi.

\section{Unity3D}

Unity adalah multi platform game engine yang dikembangkan oleh Unity Technologies. Unity sendiri mencakup game engine dan Integrated Development Environment (IDE) dalam satu paket. Unity dapat digunakan untuk membuat video game untuk website, desktop, berbagai macam konsol, dan juga perangkat bergerak.

Berbagai macam fitur ditawarkan oleh Unity, diantaranya In-built Rendering, Scripting, Asset Tracking, Asset Store, dan Physics. In-built Rendering merupakan salah satu fitur dari Unity. Unity menggunakan Beast untuk menjalankan fungsi fungsi rendering. Dengan adanya Beast, pengembang menjadi semakin mudah dalam memperbaiki tampilan scenenya tanpa harus merender di perangkat lunak tambahan

\section{E. Sketchup}

Sketchup adalah perangkat lunak pemodelan 3D yang dirancang untuk arsitek, insyinyur sipil, pembuat film, pengembang permainan, aplikasi, dan profesi lain yang terkait bidang 3D.

Keunggulan Sketchup dibanding perangkat lunak lain diantaranya adalah :

1) Antarmuka yang mudah dimengerti dan menarik, sehingga mudah digunakan bagi pemula sekalipun.

2) Dukungan berbagai open source plugin yang akan memudahkan kinerja Sketchup
3) Warehouse atau gudang model 3D yang sangat lengkap dan terorganisir sehingga memudahkan pengguna dalam mencari model 3D.

\section{PERANCANGAN SISTEM}

\section{A. Tahap-tahap dalam Pengembangan Sistem}

Sebuah karya aplikasi multimedia, tidak akan terlihat bagus apabila cerita atau ide yang disajikan dalam animasi tersebut juga tidak bagus. Pembuatan sebuah cerita atau ide yang bagus, sangat diperlukan struktur cerita yang jelas. Untuk itu, perlu dilakukan tahap pengembangan seperti dalam Gambar 1.

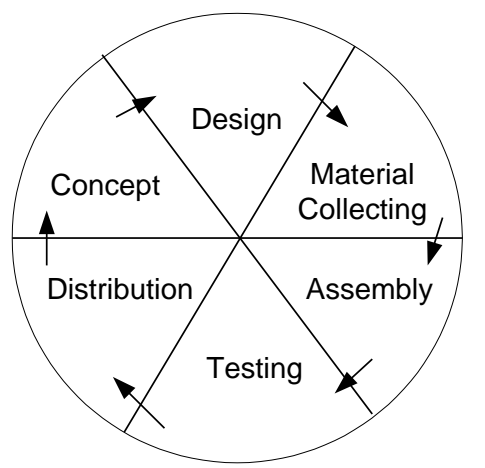

Gambar 1. Diagram pengembangan multimedia

\section{B. Analisis Kebutuhan}

Beberapa kebutuhan fungsional mengenai fitur yang harus dipenuhi dari aplikasi ini adalah :

1) Sistem dapat memberikan informasi mengenai cara menggunakan aplikasi visualisasi 3D ini.

2) Sistem dapat menampilkan kompleks Masjid Agung Jawa Tengah secara tiga dimensi dan dapat dieksplorasi sesuai keinginan penguna

3) Sistem dapat menampilkan gambar dan informasi yang berkaitan dengan Masjid Agung Jawa Tengah

4) Sistem dapat menampilkan fitur navigasi

Beberapa kebutuhan non-fungsional perihal perangkat lunak yang diperlukan dalam pengembangan aplikasi ini adalah :

1) Sistem Operasi : Microsoft Windows 732 bit

2) Unity3D

3) Sketchup

4) Editor : MonoDevelop

5) DirectX DX 9.0

\section{Desain Sistem}

Desain sistem menggunakan metode Multimedia Development Life Cycle. Perancangan sistem dibuat dengan menggunakan diagram alir.

1) Diagram alir

Diagram alir menunjukkan perubahan tampilan pada suatu layout. Transisi dari satu menu ke menu lainnya dijelaskan, hubungan antara satu halaman dengan halaman yang lain yang dinyatakan dengan garis berikut tanda panah. Diagram alir dalam aplikasi ini dapat dilihat pada Gambar 2. 


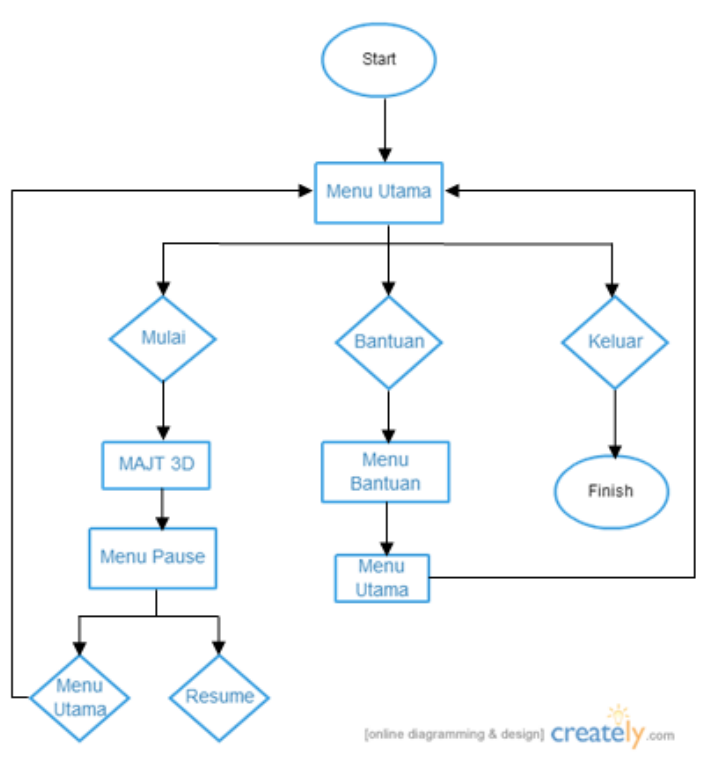

Gambar 2Diagram alir

2) Desain struktur navigasi

Struktur navigasi memberikan gambaran link dari halaman satu ke halaman lainnya. Dalam aplikasi ini desain struktur navigasi yang digunakan adalah struktur navigasi dengan hierarki model, dimana pada model ini diadaptasi dari top-down design. Konsep navigasi ini dimulai dari satu node yang menjadi halaman awal, dari halaman tersebut dapat dibuat beberapa cabang lagi. Gambar 3 menunjukkan struktur navigasi pada perancangan aplikasi visualisasi 3D InteraktifMasjid Agung Jawa Tengah.

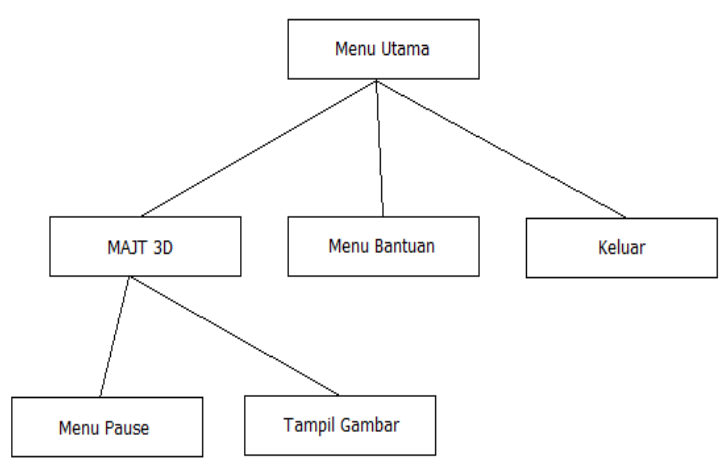

Gambar 3. Struktur navigasi perancangan aplikasi

\section{IMPLEMENTASI DAN PENGUJIAN}

\section{A. Implementasi pemodelan 3D menggunakan Sketchup}

Pemodelan 3D Masjid Agung Jawa Tengah di Sketchup dilakukan dalam beberapa tahap, yang berarti memodelkan berbagai objek kecil lalu digabungkan menjadi kompleks Masjid Agung Jawa Tengah. Dalam proses pemodelan dilakukan juga tahap teksturing yaitu pemberian tekstur pada objek yang dibuat. Untuk menghasilkan model 3 dimensi yang baik, teksturing merupakan salah satu faktor yang sangat penting baik dalam segi performansi maupun segi keindahan model 3 dimensi tersebut.. Dalam pemodelan Masjid Agung Jawa Tengah, objek yang dibuat diantaranya halaman parkir, halaman utama, pilar, menara, parkir bawah, halaman belakang, dan bangunan utama.

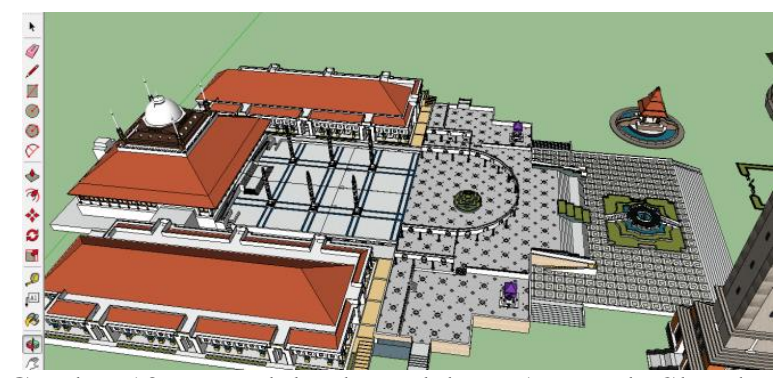

Gambar 10. Pemodelan kompleks MAJT pada Sketchup

\section{B. Implementasi pada Unity3D}

Implementasi di perangkat lunak Unity3D dilakukan dengan mengimpor berkas .FBX ke ruang kerja di Unity 3D. Pengaturan dilakukan dengan mengubah skala menjadi 1 (default 0.01), optimasi mesh, membuat collider, dan $U V$ map. Skala 1 diperlukan agar model yang diimpor memiliki ukuran yang sama dengan yang diharapkan, karena dengan default 0.01 model yang sudah memiliki skala yang tepat pada Sketchup akan menjadi sangat kecil pada Unity3D. Selanjutnya optimasi mesh digunakan untuk menyederhanakan model agar tidak membebani kinerja memori ketika dibuka. Collider merupakan benturan yang diperlukan agar nantinya karakter tidak dapat berjalan menembus dinding dalam model. Ini merupakan cara yang ringkas untuk memberikan collider pada setiap objek pada model yang telah dibuat karena pemberian collider secara manual dapat menyita banyak waktu meskipun hasilnya dapat ditentukan sesuai pengguna. Sedangkan $U V$ map adalah berkas tekstur.

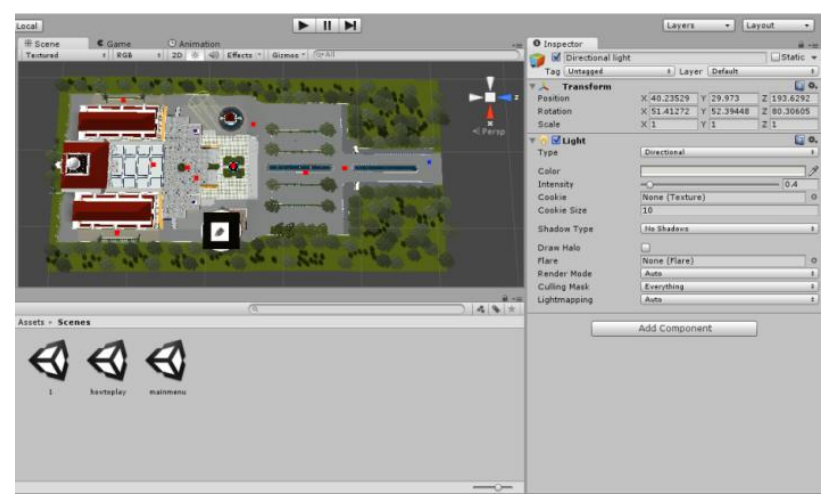

Gambar 11. Implementasi pada Unity3D

Alur kerja pada Unity3D yaitu berupa penambahan karakter bertipe sudut pandang orang pertama, menambahkan pencahayaan, mengatur Terrain, menambahkan objek berupa pohon, menambahkan skrip, 
zona trigger, hingga proses render dan build. Berikut merupakan beberapa tampilan menu yang ada pada aplikasi visualisasi 3D Masjid Agung Jawa Tengah, yang terdiri dari Menu Utama, Menu Bantuan, dan Menu Pause.

\section{1) Menu Utama}

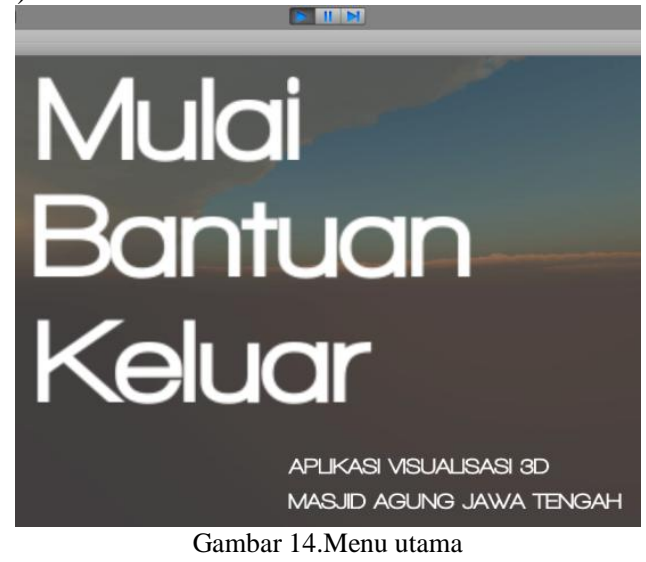

2) Menu Bantuan

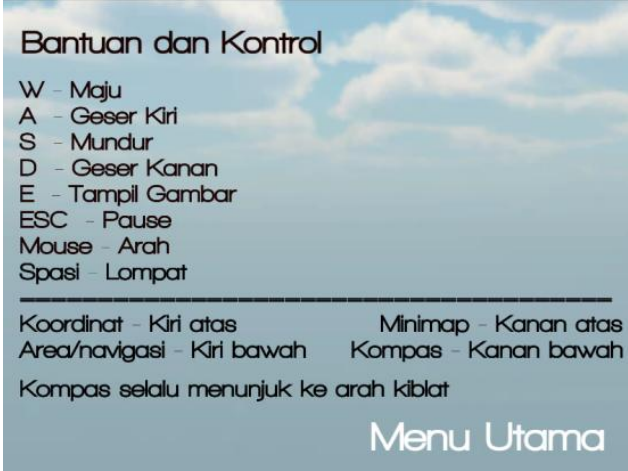

Gambar 15. Menu Bantuan

\section{3) Menu Pause}

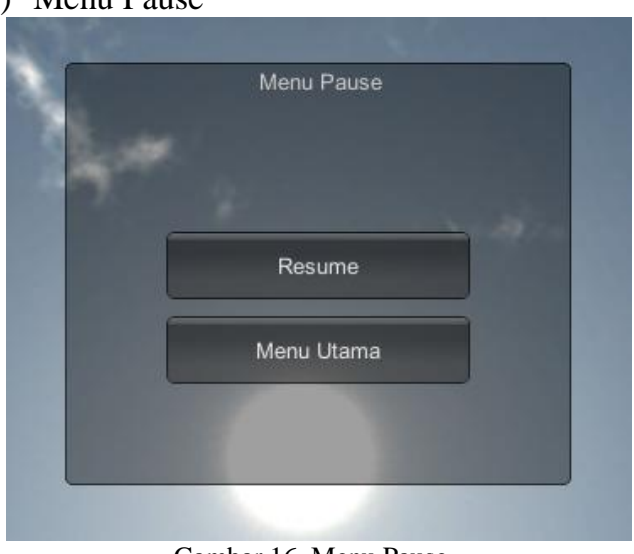

Gambar 16. Menu Pause

Berikut merupakan tampilan beberapa scene yang ada dalam aplikasi visualisasi Masjid Agung Jawa Tengah.
1) Scene area parkir MAJT

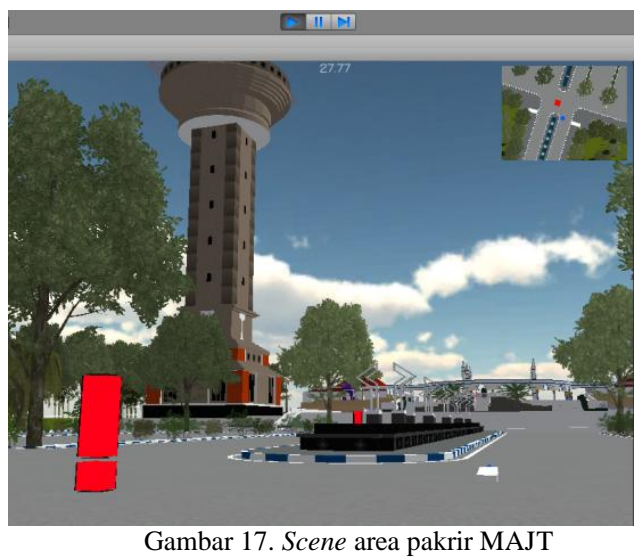

2) Scene area halaman depan MAJT

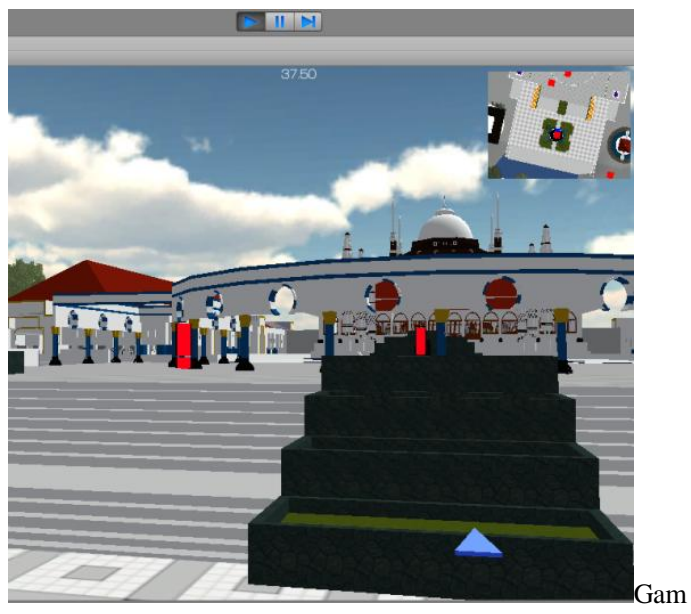

bar 18. Scene area halaman depan MAJT

\section{Pengujian}

1) Pengujian Blackbox

Pengujian pertama yang dilakukan pada Tugas Akhir ini menggunakan metode black box yaitu menguji fungsionalitas dari perangkat lunak saja tanpa harus mengetahui struktur internal program (source code).

Pengujian aplikasi ini dilakukan dengan menggunakan metode black-box.Tahap ini berisi serangkaian pengujian fungsi dan tombol pada. Cara pengujiannya hanya dilakukan dengan nekan tombol yang akan diuji, kemudian diamati apakah hasilnya sesuai dengan spesifikasi kebutuhan. Fungsi-fungsi yang dapat dilakukan permainan yaitu menampilkan menu utama, tombol mulai, tombol bantuan, tombol keluar, menu pause, dan tampil gambar. Sedangkan tombol pada kontroler yang diuji adalah spasi, W,S,A,D,E, tombol mouse kiri, dan Escape.

Hasil pengujian terhadap fungsi-fungsi dan tombol-tombol permainan menunjukkan hasil uji "Berhasil". Artinya secara fungsional, permainan sudah berjalan sesuai dengan spesifikasi kebutuhan dan skenario permainan. 
2) Pengujian waktu non real time rendering dan penggunaan CPU-RAM

Pengujian non real time rendering dilakukan dengan cara melakukan bake texture scene MAJT3D pada Unity3D. Pengujian dilakukan dengan menguji lama waktu proses render dari beberapa pengaturan dan mencatat proses penggunaan CPU dan RAM selama proses berjalan. Hasil dari pengujian dpat dilihat pada Tabel 1.

TABEL 1. TABEL HASIL PENGUJIAN WAKTU NON REAL TIME RENDERING DAN PENGGUNAAN CPU-RAM

\begin{tabular}{|l|l|l|l|}
\hline $\begin{array}{l}\text { Pengaturan } \\
\text { kualitas } \\
\text { render }\end{array}$ & $\begin{array}{l}\text { Lama } \\
\text { Render }\end{array}$ & $\begin{array}{l}\text { Penggunaan } \\
\text { CPU }\end{array}$ & $\begin{array}{l}\text { Penggunaan } \\
\text { RAM }\end{array}$ \\
\hline $\begin{array}{l}\text { Dual } \\
\text { Lightmap } \\
\text { High Quality }\end{array}$ & $\begin{array}{l}\text { 5 Jam 14 } \\
\text { Menit }\end{array}$ & $93,1 \%$ & $415 \mathrm{MB}$ \\
\hline $\begin{array}{l}\text { Dual } \\
\text { Lightmap } \\
\text { Low Quality }\end{array}$ & 44 Menit & $79,2 \%$ & $668 \mathrm{MB}$ \\
\hline $\begin{array}{l}\text { Single } \\
\text { Lightmap } \\
\text { High Quality }\end{array}$ & $\begin{array}{l}\text { Menit } \\
\text { Jamgle }\end{array}$ & $91,8 \%$ & $422 \mathrm{MB}$ \\
\hline $\begin{array}{l}\text { Lightmap } \\
\text { Low Quality }\end{array}$ & 42 Menit & $74,9 \%$ & $658 \mathrm{MB}$ \\
\hline $\begin{array}{l}\text { Single } \\
\text { Lightmap } \\
\text { Low Quality } \\
\text { No Ambient } \\
\text { Occlussion }\end{array}$ & 9 Menit & $26,6 \%$ & $483 \mathrm{MB}$ \\
\hline
\end{tabular}

3) Pengujian penggunaan prosesor dan RAM pada Aplikasi

Pengujian penggunaan prosesor dan RAM saat aplikasi dijalankan dilakukan dengan menggunakan perangkat lunak Average CPU Cycle dan Kiwi Application Monitor. Aplikasi dijalankan seperti biasa selama beberapa menit dan hasilnya dapat dilihat pada kedua perangkat lunak tersebut. Hasil pengujian dapat dilihat pada Gambar 19

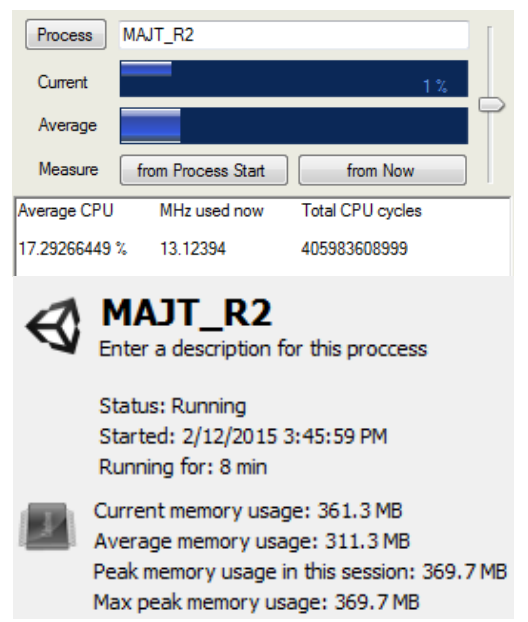

Gambar 19. Pengujian penggunaan CPU-RAM aplikasi

Hasil pengujian menunjukkan bahwa rata-rata penggunaan prosesor dan RAM pada aplikasi yang dijalankan selama 8 menit adalah $17,3 \%$ dan $311 \mathrm{MB}$.

\section{4) Pengujian Pengguna}

Pengujian pengguna dilakukan dengan mengambil tanggapan dari 10 pengguna. Pengujian dilakukan dengan meminta pengguna menjalankan aplikasi dan memberikan tanggapan atas pertanyaan mengenai aplikasi. Hasil pengujian pengguna dapat dilihat pada Tabel 2 .

TABEL 2. TABEL HASIL PENGUJIAN PENGGUNA

\begin{tabular}{|l|l|c|}
\hline \multicolumn{1}{|c|}{ Pertanyaan } & Kriteria Jawaban & $\begin{array}{c}\text { Jumlah Tanggapan } \\
\text { Pengguna }\end{array}$ \\
\hline \multirow{4}{*}{$\begin{array}{l}\text { Kemudahan } \\
\text { Aplikasi }\end{array}$} & Sangat Mudah & - \\
\cline { 2 - 3 } & Mudah & 3 \\
\cline { 2 - 3 } & Cukup Mudah & 5 \\
\cline { 2 - 3 } & Kurang Mudah & 2 \\
\cline { 2 - 3 } & Tidak Mudah & - \\
\hline \multirow{4}{*}{$\begin{array}{l}\text { Manfaat Aplikasi } \\
\text { Kemiripan }\end{array}$} & Sangat Bermanfaat & - \\
\cline { 2 - 3 } & Bermanfaat & 8 \\
\cline { 2 - 3 } & Cukup Bermanfaat & - \\
\cline { 2 - 3 } & Kurang Bermanfaat & - \\
\cline { 2 - 3 } & Tidak Bermanfaat & - \\
\hline \multirow{5}{*}{} & Sangat Mirip & 3 \\
\cline { 2 - 3 } & Mirip & - \\
\cline { 2 - 3 } & Cukup Mirip & - \\
\cline { 2 - 3 } & Kurang Mirip & \\
\cline { 2 - 3 } & Tidak Mirip & \\
\hline
\end{tabular}

\section{KESIMPULAN DAN SARAN}

\section{A. Kesimpulan}

Dari hasil pengujian dan analisis yang telah dilakukan pada aplikasi Visualisasi 3D Interaktif Masjid Agung Jawa Tengah dapat diberikan beberapa kesimpulan sebagai berikut.

1) Aplikasi visualisasi 3D interaktif Masjid Agung Jawa Tengah cukup mudah untuk dijalankan oleh pengguna.

2) Aplikasi visualisasi 3D interaktif Masjid Agung Jawa Tengah bermanfaat bagi pengguna untuk dapat mengetahui tentang kompleks Masjid Agung Jawa Tengah dan info-info didalamnya.

3) Berdasarkan pengujian pada aplikasi visualisasi 3D interaktif Masjid Agung Jawa Tengah, obyek-obyek yang ada dalam aplikasi sudah cukup mirip dengan obyek-obyek asli dalam Masjid Agung Jawa Tengah.

4) Aplikasi dapat berjalan pada sistem operasi Windows dengana menjalankan berkas .exe.

5) Setiap fungsi dan tombol-tombol yang ada dalam aplikasi ini telah berjalan sesuai dengan perancangan.

6) Berdasarkan pengujian yang telah dilakukan dapat ditunjukkan bahwa proses Real time rendering merupakan proses yang membutuhkan kinerja kartu grafis yang tinggi, sedangkan proses non real time rendering (offline rendering) lebih membutuhkan kinerja prosesor.

\section{B. Saran}

Dari hasil pengujian dan analisis yang telah dilakukan pada aplikasi Visualisasi 3D Interaktif Masjid Agung Jawa Tengah dapat diberikan beberapa saran sebagai berikut. 
1) Aplikasi Visualisasi 3D Interaktif Masjid Agung Jawa Tengah ini dapat dikembangkan lebih lanjut dengan membuat model 3 dimensi tampilan dari bagian dalam bangunan utama yang berada pada kompleks MAJT.

2) Perlu dilakukan penelitian lebih lanjut mengenai cara membuat model 3D dan teksturing yang efisien sehingga dapat menghasilkan model 3D dengan detil yang baik dan performansi yang cepat.

3) Perlu dilakukan penelitian lebih lanjut mengenai cara optimasi laju bingkai per detik pada komputer dengan spesifikasi rendah sehingga dapat menghasilkan aplikasi yang dapat dijalankan pada berbagai spesifikasi dengan lancar.

\section{DAFTAR PUSTAKA}

[1] Ardhianto, Eka., W. Hadikurniawati, dan E.Winarno. 2012 Augmented Reality Objek 3 Dimensi dengan perangkat Artoolkit dan Blender. Jurnal Teknologi Informasi DINAMIK. 17(2), 108-109

[2] Bertoline, Gary. 2013. Fundamental of Graphic Communication. Cram 101

[3] Boeykens, Stefan. 2013. Unity for Architectural Visualization (chapter 2). Packt Publishing
[4] Chopra, Aidan. 2009. Google Sketchup for Dummies. Wiley Publishing

[5] De Jongh, Robin. 2011. Google Sketchup for Game Design. Packt Publishing

[6] Henson Craighton, Ryan. 2010. Unity3D Game Development by Example. Packt Publishing

[7] Masjid Agung Jawa Tengah. Diakses pada 4 Oktober 2014.http://id.wikipedia.org/wiki/Masjid_Agung_Jawa_Ten gah

[8] Mc. Cormick, Bruce. 1987. Visualization in Scientific Computing. Computer Graphic Vol.21

[9] Moedjiono. 1992. Media pendidikan III: Cara Pembukaan Media Pendidikan. Jakarta: P3G. Depdikbud.

[10] Rendering (Computer Graphic). Diakses pada 4 Oktober2014.http://en.wikipedia.org/wiki/Rendering_(comp uter_graphics)

[11] Suwantoro, Gamal. 1997. Dasar-Dasar Pariwisata. Andi Publishing

[12] Unity Scripting. Diakses pada 8 November 2014. http://docs.unity3d.com/ScriptReference 